\title{
Юбилей корифея экономической географии (90-летие Г. В. Сдасюк)
}

\author{
Н.Н. Клюев ${ }^{1 凶}$, Т. М. Худякова ${ }^{2}$, А.Н. Васильцова ${ }^{1}$ \\ ${ }^{1}$ Институт географии РАН, Российская Федераџия \\ (119017, г. Москва, Старомонетный переулок, 29) \\ ${ }_{2}^{2}$ Воронежский государственный педагогический университет, Российская Федерачия \\ (394043, г. Воронеж, ул. Ленина, 86)
}

\begin{abstract}
Аннотация. Представлена творческая биография Г.В. Сдасюк - одного из лидеров отечественной экономической географии. Показан ее вклад в становление и развитие комплексного страноведения, географии Индии, географической глобалистики, географических аспектов устойчивого развития.

Ключевые слова: Г.В. Сдасюк, биография, Институт географии РАН, Индия, устойчивое развитие, страноведение.

Для цитирования: Клюев Н. Н., Худякова Т. М., Васильцова А.Н. Юбилей корифея экономической географии (90-летие Г. В. Сдасюк) // Вестник Воронежского государственного университета. Серия: География. Геоэкология, 2021 № 4, с. 120-125. DOI: https://doi.org/10.17308/geo.2021.4/3760
\end{abstract}

В 2021 году «красная» дата географического календаря - 90-летний юбилей Галины Васильевны Сдасюк. Галина Васильевна - доктор географических наук, профессор, ведущий научный сотрудник лаборатории географии мирового развития Института географии РАН, руководитель многих комплексных географических проектов, автор, соавтор и редактор сотен научных трудов, включая десятки книг, подлинный корифей экономической географии.

Галина Васильевна поступила на географический факультет МГУ в 1949 году, а в 1954 году его окончание было первым выпуском советских географов в новом здании МГУ на Ленинских горах Москвы. Сдасюк окончила кафедру экономической географии СССР. Она - одна из блистательной когорты учеников основоположника отечественной экономической географии Н.Н. Баранского. Под его руководством в 1957 году успешно защитила кандидатскую диссертацию, посвященную проблемам развития Восточно-Сибирского региона и его главного центра - города Иркутска. Диссертационная работа ею написана в основном на полевом материале, собранном в экспедиции МГУ, в которой она участвовала в течение пяти полевых сезонов на старших курсах и в аспирантуре.
В конце 1950-х годов, когда развернулось активное сотрудничество ССCP, возглавлявшего страны лагеря социализма, и Индией, стоявшей во главе неприсоединившихся стран, потребовались специалисты, знающие географию этой страны. В 1958 году Г. В. Сдасюк была приглашена на кафедру экономической географии зарубежных стран географического факультета МГУ для подготовки учебного пособия по Индии, а в 1959 году командируется в Индию по программе научного и культурного обмена. По прошествии года ее пригласили на работу в Отдел региональных исследований Индийского статистического института при Плановой комиссии Индии, которую интересовал советский опыт районирования для планирования и возможности его использования в этой стране. Тогда же началось сотрудничество Галины Васильевны с индийским географом Ф.Сен Гута, возглавлявшей отдел географии и картографии Организации по переписи населения Индии. В 1968 году опубликована их совместная книга «Экономическое районирование Индии: проблемы и подходы» (научный консультант В.В. Покшишевский), представленная на Международном географическом конгрессе, состоявшемся в тот год в Дели. Эта книга широко известна в плановых органах и на географических

(C) Клюев Н.Н., Худякова Т. М., Васильцова А.Н., 2021

\ Клюев Николай Николаевич, e-mail: klyuev@igras.ru

Контент доступен под лицензией Creative Commons Attribution 4.0 License. 
факультетах Индии. По запросу индийской стороны она переиздана в 1994 году.

По возвращении из зарубежной командировки с 1962 года Г.В. Сдасюк работает в Институте географии АН СССР (ныне РАН). В 1975 году Галина Васильевна защитила докторскую диссертацию на тему «Индия: развитие территориальной структуры хозяйства в ходе преодоления колониального характера экономики». На основе диссертационного исследования опубликована монография, за которую её автору присуждена Золотая медаль им. Н. М. Пржевальского Всесоюзного географического общества.

Отличительная черта творчества Г.В. Сдасюк - интегральный социо-эколого-экономический характер ее трудов, поиск путей общегеографического синтеза.

Галина Васильевна является одним из ярких представителей отечественной географической школы комплексного проблемного страноведения, основанной Н.Н. Баранским и И. А. Витвером и имеющей высокий авторитет в мировой географии. Её книги $[1-5,12]$ имеют большое методологическое и конкретно-географическое значение. Они высоко ценятся и индийскими учеными, поддерживающими с Г.В. творческие контакты.

В Индии при активном участии юбиляра опубликовано пять географических индо-советских книг - результаты совместных семинаров и конференций по проблемам регионального развития и планирования.

Г.В. Сдасюк-участник многих других знаковых международных проектов. Она была заместителем председателя программного комитета Международного географического конгресса (г. Москва, 1976). Участвовала в 1976-1989 годах в польско-советском сотрудничестве по географическим проблемам развивающихся стран. По заказу Центра региональных исследований ООН в 1985 году подготовила (совместно с С.Б. Лавровым и В.В. Покшишевским) книгу «Районирование для планирования в СССР: концепции, методы, практика» [5]. Вместе с В.М. Котляковым и Г. Уайтом руководила российско-американским проектом, итогом которого стала книга «Глобальные изменения: географические подходы» (1991 г.), опубликованная в СССР и США.

Серьезной вехой в творческой биографии Г.В. Сдасюк послужил выход книги «Этот контрастный мир» (совместно с С.Б. Лавровым) [6]. Прекрасно оформленная и богатая по содержанию монография - первая попытка географического осмысления глобальных проблем, их социально-экономических и экологических аспектов. Книгой заложены основы географической глобалистики - отрасли науки, которая активно развивается. Заметим, что в 1980-е годы, когда вышла в свет эта книга, процесс, который позднее был назван «глобализацией», тогда ещё не получил развития. Ныне теоретико-методические подходы, разработанные Г.В. Сдасюк с соавтором, стали эффективным исследовательским инструментом для анализа этого сложного и неоднозначного феномена современности. Вместе с тем, «Этот контрастный мир» написан в хорошем смысле «популярно», что позволяет использовать книгу широким кругом читателей.

Достигнув немалых научных высот в области страноведения и географической глобалистики, Г.В. Сдасюк активно занимается актуальнейшей экологической проблематикой, вопросами природопользования и устойчивого развития. Совместно с А. А. Тишковым ею предложена концепция «ключевых регионов устойчивого развития», которая представляется нам весьма плодотворной в научном, познавательном и в практическом отношении.

В 1990-е годы трагического распада СССР и распада многих хозяйственных структур Г.В. Сдасюк концентрирует внимание на изучение международного опыта перехода к устойчивому развитию и целесообразности его использования в отдельных районах России.

В качестве исследовательского полигона для апробирования модели выступал Невельский район Псковской области. Г.В. Сдасюк - руководитель и один из основных разработчиков проекта «Невель-XXI», модели перехода к устойчивому развитию на локальном уровне. Разработка модели потребовала объединения усилий как учёных Института географии РАН и Великолукской государственной сельскохозяйственной академии, так и местных органов власти. Исследования на локальном уровне чрезвычайно важны в силу того, что именно здесь формируется территориальная мозаика природопользования, ключевые социально-экономические и экологические проблемы. В ходе реализации данного проекта разработаны конструктивные рекомендации по выходу из кризиса и переходу к устойчивому развитию. Они опубликованы как учебное пособие проекта Министерства сельского хозяйства РФ ТАСИС «Укрепление реформ в сельском хозяйстве посредством образования» [8].

Г.В. Сдасюк выступала инициатором, организатором, ответственным редактором и одним из основных авторов пяти коллективных монографий 
серии ИГ РАН «Устойчивое развитие: проблем и перспективы», вышедших в 2002-2012 годах. При подготовке этих солидных томов Г.В. Сдасюк проявила себя и теоретиком, и географом-практиком, мастерски анализирующим геосистемы разного иерархического уровня - от глобального до локального. Отметим и заслугу Г.В. Сдасюк как научного менеджера, обеспечившего при реализации данного проекта успешную работу междисциплинарного коллектива, насчитывающего в совокупности почти сотню исследователей из многих академических институтов, вузов, а также специалистов-практиков.

Отметим научные контакты Г.В. Сдасюк с учеными - географами города Воронежа 2005-2012 годах (Воронежский госуниверситет, Воронежский госпедуниверситет) - с профессорами Т. М. Худяковой, Ю. В. Поросенковым, В.Б. Михно.

Как руководитель проекта Галина Васильевна четко определила рекомендации анализа социально-экономических и экологических показателей производства. Центральное Черноземье - один из успешно развивающихся районов в области сельскохозяйственного производства, являясь крупной продовольственной базой страны. Второе важное успешно развивающееся направление хозяйственной деятельности района - формирование железорудно-металлургического комплекса нашего государства. На основе железорудных запасов КМА здесь сложился мощный индустриальный комплекс по выплавке стали путем прямого восстановления железной руды в конечный продукт.

Программой изучения регионов предусматривался поиск и обоснование путей устойчивого развития на основе новых технологий. Галина Васильевна Сдасюк выступила на конференции «Территориальная организация общества и управления в регионах» (октябрь 2016 год). Были прочитаны лекции и проведены семинары для студентов и магистров географической специальности. В период конференции Галина Васильевна совместно с ее участниками посетила Воронежский государственный природный биосферный заповедник им. В.М. Пескова. Она приняла также участие в экскурсии по г. Боброву, посвященной ознакомлению с объектами историко-культурного наследия, которыми так насыщен город.

В журнале «Вестник Воронежского государственного университета. Серия: География. Геоэкология», 2016 г., № 4, была опубликована статья Г.В. Сдасюк «Школа Н.Н. Баранского и современные проблемы перехода России к устойчивому региональному развитию». Статья получила особенно высокую оценку редакции журнала Earth Sciences (Науки о Земле), написавшей об этом автору с приглашением публиковать в этом журнале ее работы.

Г.В. Сдасюк - очень контактный учёный, среди её соавторов - крупнейший специалист по зарубежной географии С.Б. Лавров [8-10], геохимик и геоэколог Н.Ф. Глазовский, картограф А.А. Лютый, геополитик В.А. Колосов, биогеограф А.А. Тишков, американский географ-универсал энвайронменталист Гилберт Уайт и многие другие представители чуть ли не всех географических специальностей.

Галина Васильевна - искусный полемист и прекрасный оратор. Её выступления на Учёных и диссертационных советах, конференциях и симпозиумах отличаются серьёзной аргументацией, эмоциональностью и яркой образностью.

Г.В. Сдасюк в 1990-2008 годах преподавала в Великолукской сельскохозяйственной академии, в 2000-х годах читала курсы лекций в Московском государственном социальном университете. По приглашению вела преподавательскую работу в Индии, республике Бангладеш, Непале, в Лондонской школе экономики, Институте ресурсов (г. Вашингтон, США). По линии Всесоюзного общества «Знание» посетила с лекциями много регионов Советского Союза, опубликовала ряд научно-популярных брошюр, посвященных сотрудничеству СССР с развивающимися странами.

Большую научно-организационную работу Г.В. Сдасюк ведет и в Русском географическом обществе (ранее ВГО), несколько десятилетий она возглавляла в его Московском филиале отделение экономической и политической географии. Г.В. Сдасюк - почетный член РГО. Она награждена Российской экологической академией медалью М.В. Ломоносова «За вклад в науку и экологию» (2018 г.).

Отрадно, что старейшина отечественных экономико-географов до сих пор в «научной форме» и в свой юбилейный год опубликовала новую большую монографию (36 п.л.) «Новая Индия. География развития. Достижения, проблемы, перспективы» [12]. В ней обобщены итоги ее более полувековых исследований этой страны. «Новая Индия» - образец классического комплексного географического страноведения, расцветавшего в советские годы, но ныне практически сошедшего на нет. Между тем в наш век глобализации и стремительного роста взаимосвязей и взаимозависи- 
мости национальных экономик значение страноведения и ценность сравнительных межстрановых исследований только возрастает.

Поскольку новая монография Г.В. Сдасюк вышла в свет недавно - в юбилейный год автора, остановимся на ней несколько подробнее. Книга отличается широтой охвата проблематики и одновременно глубиной проработки каждой темы - оба этих достоинства нечасто соседствуют в рамках одного исследования. Структура книги соответствует стилю классического страноведения, но отличается от них упором на анализ новых факторов развития «глобализирующейся» Индии.

Работа состоит из цепи исследовательских «миниатюр», где последовательно рассматриваются все аспекты географической картины страны: общественная формация, меняющееся геополитическое и экономико-географическое положение, демография, экологическая ситуация, сельское хозяйство, промышленность, транспорт, торговля, региональная политика.

В предисловии к монографии представлено становление и развитие советско-индийского (впоследствии российско-индийского) научного географического сотрудничества, ключевая роль в котором принадлежала и принадлежит Галине Васильевне.

Анализируя различные аспекты процесса развития Индии, автор приходит к выводу, что ключевое влияние на него имеет система государственного управления. Прежняя колониальная модель способствовала ускоренной деградации народного хозяйства: за два столетия зависимости от Великобритании доля Индии в мировом ВВП сократилась с четверти до 4\% [12, с.77]. Индийские достижения и успехи второй половины ХХ в. - это результат прежде всего научно обоснованной государственной системы планирования. Индийское государство не идёт проторенной дорогой догоняющего развития, оно прокладывает свой путь, основываясь на собственной экономико-географической специфике. Ведь Индия, по меткому выражению Г. В. Сдасюк, - это «страна-цивилизация».

Одним из значимых конкурентных преимуществ изучаемого социума автор называет наличие в нём самого многочисленного на Земле молодого поколения, что в то же время представляет и сложную проблему обеспечения его занятости, повышения квалификации при низком уровне базового образования. Молодежь, получившая соответствующую квалификацию, мастерски владеет цифровыми технологиями и программированием, наибо- лее перспективными и востребованными профессиями постиндустриального мира. Это во многом определяет специализацию третичного сектора индийской экономики, в результате индийское государство может ставить даже такие амбициозные задачи, как достижение всеобеей цифровой грамотности в 2023 году. «Свой путь» уже даёт ощутимые позитивные результаты. Так, Индии удалось перескочить через два поколения финансовых технологий и выйти на цифровой банкинг, создать крупнейший интернет-рынок и занять лидирующие позиции по компьютерному аутсорсингу.

Г.В. Сдасюк раскрывает представление о «географической фрагментации производственных процессов», приходящей в условиях глобализующегося мира на смену производственно-территориальному комплексированию. Концепция «географической фрагментации», глобальных стоимостных цепочек, формирования межгосударственных транспортно-экономических коридоров обогащает теорию территориальной организации мирового хозяйства в 21-м веке. Активизацию участия в процессах глобализации Индия определяет как магистральный путь своего развития, максимизируя выгоды такого участия и сокращая риски глубокого вовлечения в международное разделение труда.

В книге убедительно показано, что Индия - это место, где скрещиваются многие глобальные проблемы человечества. Это зона контрастов и противоречий. Первая в истории страна (ещё при Махатме Ганди), провозгласившая идеалы устойчивого развития, сегодня «плетётся в хвосте» по уровню их реализации. Она является мировым лидером по скорости экономического роста и занимает одно из последних мест по ответственному природопользованию. Для Индии характерны колоссальные внутренние контрасты. Региональные диспропорции развития в период глобализации возрастают. Это усиливает значение проблем региональных исследований и проблем интеграции страны на основе перехода к устойчивому развитию на всех уровнях - от глобального до локального.

«Новая Индия. География развития», несомненно, представляет большой интерес профессиональным географам и обществоведам самых разных специальностей, а также всем, кто неравнодушен к индийской культуре, к стране, с которой Россия имеет уникальный, доверительный и взаимовыгодный характер.

Поздравляем Галину Васильевну со славным юбилеем! Желаем здоровья и новых творческих успехов, новых учеников и последователей! 


\section{СПИСОК ОПУБЛИКОВАННЫХ КНИГ}

1. Баталов А. Л, Княжинская Л.А., Сдасюк Г.В. Южная Индия. Экономико-географическая характеристика. М.: Мысль, 1966. 276 с.

2. Gupta P., Sdasyuk Galina. Economic Regionalizaton of India: Problems and Approaches. Census of India 1961. Monograph Series New Delhi. 1968. 257 p.

3. Карпов Л.Н., Сдасюк Г.В., Уткин Г.Н. Основные направления и некоторые итоги региональных экономических исследований в системе ООН (Аналитический обзор). М. 1973. 137 с.

4. Сдасюк Г.В. Индия: география хозяйства (Развитие территориальной структуры хозяйства в ходе преодоления колониального характера экономики). М.: Мысль, 1975. 367 с.

5. Сдасюк Г.В. Штаты Индии. Природа, население, хозяйство, города. М.: Мысль, 1981. 368 с.

6. Lavrov S. B., Pokshishevsky V. V., Sdasyuk G.V. (Eds.) Regionalization for Planning in the USSR. Concepts, Methods and Practice. UN. Centre for Regional Development. Nagoya Japan. 1985. 273 p.

7. Лавров С.Б., Сдасюк Г. В. Этот контрастный мир. Географические аспекты некоторых глобальных проблем. М.: Мысль, 1985. 207 с.
8. Емельянов В.А., Сдасюк Г.В., Спасов В.П. Переход к устойчивому развитию сельского хозяйства и сельских территорий: локальный уровень. Учебное пособие. Интерактивная форма. Министерство сельского хозяйства РФ. Проект ТАСИС «Укрепление реформ в сельском хозяйстве посредством образования». М. 2001. 73 с.

9. Hönsch, Fritz., Lavrov Sergey, Sdasyuk Galina. Bürgerliche Konzeption der Regionalen Entwicklung. Haack, Gotha. 1986. 148 c.

10. Золотарев В., Лавров С., Сдасюк Г. Порог необратимости (на порт. яз.). М.: Прогресс, 1988. 165 с.

11. Lavrov S.B., Sdasyuk G.V. Concepts of Regional Development. М.: Прогресc, 1989. 219 c. (на англ. яз., тамили).

12. Сдасюк Г.В. Новая Индия. География развития: достижения, проблемы, перспективы: монография (Серия «География мирового развития»). М.: Канон+ РООИ «Реабилитация», 2021. 520 с.

Конфликт интересов: Авторы декларируют отсутствие явных и потенциальных конфликтов интересов, связанных с публикацией настоящей статьи.

Поступила в редакцию 15.04.2021 Принята к публикации 23.11.2021

\title{
Jubilee of the Coryphaeus of Economic Geography (90th Anniversary of G.V. Sdasyuk)
}

\author{
N.N. Klyuev ${ }^{1 凶}$, T. M. Khudyakova ${ }^{2}$, A.N. Vasiltsova ${ }^{1}$ \\ ${ }^{1}$ Institute of Geography of the Russian Academy of Sciences, Russian Federation \\ (29, Staromonetny Pereulok, Moscow, 119017) \\ ${ }^{2}$ Voronezh State Pedagogical University, Russian Federation \\ (86, Lenin Str., Voronezh, 394043)
}

\begin{abstract}
The article presents creative biography of G.V. Sdasyuk, one of the leaders of national economic geography. Her contribution to formation and development of complex country study, geography of India, geographical globalistics, geographical aspects of sustainable development is shown.

Key words: G.V. Sdasyuk, biography, Institute of Geography of the Russian Academy of Sciences, India, sustainable development, country studies.

For citation: Klyuev N. N., Khudyakova T.M., Vasiltsova A. N. Jubilee of the Coryphaeus of Economic Geography (90th Anniversary of G.V. Sdasyuk). Vestnik Voronezskogo gosudarstvennogo universiteta. Seria: Geografia geoekologia, 2021, no. 4, pp. 120-125 (In Russ.) DOI: https://doi.org/10.17308/geo.2021.4/3760
\end{abstract}

(C) Klyuev N.N., Khudyakova T.M., Vasiltsova A.N., 2021

\ Nikolay N. Klyuev, e-mail: klyuev@igras.ru

The content is available under Creative Commons Attribution 4.0 License. 
Conflict of interests: The author declares no information of obvious and potential conflicts of interest related to the publication of this article.

Received: 15.04 .2021

Accepted: 23.11.2021

Клюев Николай Николаевич

доктор географических наук, ведущий научный сотрудник Института географии РАН, г. Москва, Российская Федерация, ORCID: 0000-0002-9247-9252, e-mail: klyuev@igras.ru

Худякова Тамара Михайловна

доктор географических наук, профессор, профессор кафедры географии и туризма Воронежского государственного педагогического университета, г. Воронеж, Российская Федерация, ORCID: 0000-0001-5773-4871, e-mail: ekgeo.vspu@yandex.ru

Васильцова Анна Николаевна

инженер-исследователь Института географии РАН, г. Москва, Российская Федерация, e-mail: vasilcova@, igras.ru
Nikolay N. Klyuev

Dr. Sci. (Geogr.), Leading Scientific Researcher, Institute of Geography of the RAS, Moscow, Russian Federation, ORCID: 0000-0002-9247-9252, e-mail: klyuev@igras.ru

\section{Tamara M. Khudyakova}

Dr. Sci. (Geogr.), Professor, Professor of Geography and Tourism Department, Voronezh State Pedagogical University, Voronezh, Russian Federation, ORCID: 00000001-5773-4871, e-mail: ekgeo.vspu@yandex.ru

Anna N. Vasiltsova

Research Engineer, Institute of Geography of the RAS, Moscow, Russian Federation, e-mail: vasilcova@igras.ru 